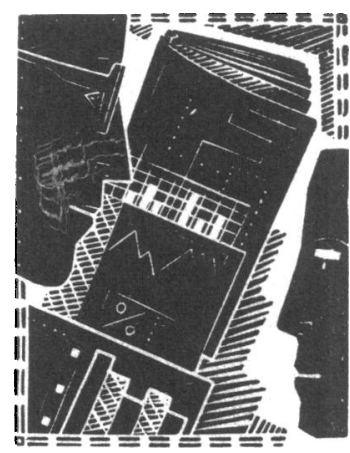

Department of Cardiology, Derriford Hospital, Plymouth PL6 8DH

Timothy J Hendra, MRCP, senior registrar

Andrew J Marshall, FRCP, consultant

Correspondence and requests for reprints to: Dr T J Hendra,

Department of Care of the Elderly, Frenchay Hospital, Bristol BS16 1LE.

\title{
Increased prescription of thrombolytic treatment to elderly patients with suspected acute myocardial infarction associated with audit
}

\author{
Timothy J Hendra, Andrew J Marshall
}

\section{Abstract}

Objectives-To assess prescription of thrombolytic treatment to elderly patients with suspected acute myocardial infarction and the incidence of side effects.

Design-Retrospective analysis of prescriptions during five months (first audit) followed by prospective analysis of uptake of treatment during five months after interventions in clinical management; prospective assessment of adverse events during thrombolytic treatment.

Setting-Coronary care unit of large district general hospital.

Patients-110 patients aged $\geqslant 65$ with subsequently proved acute myocardial infarction admitted in first audit and 119 admitted in the second.

Main outcome measures-Site of infarct, prescription of thrombolysis treatment, reasons for nonprescription, complications.

Results-Before intervention thrombolytic treatment was prescribed to $13 / 110(12 \%)$ patients with subsequently confirmed myocardial infarction and after intervention to $55 / 119(46 \%)$ patients $(p<0.01)$. In the first audit no patients with angina received thrombolytic treatment whereas $13 / 79(16 \%)$ were treated in the second audit. Increased prescription of thrombolytic treatment in the second audit was associated with significantly fewer exclusions owing to dyspepsia $(p<0.05)$ and unstated or unsatisfactory reasons $(p<0.01)$ Streptokinase infusions were completed uneventfully in $75 \%(48 / 64)$ and $77 \%$ $(10 / 13)$ of patients with infarction and angina respectively. Side effects of treatment were more common in patients with inferior than with anterior infarcts $(16 / 42(30 \%) v 3 / 24(13 \%), p<0.05)$.

Conclusions-Low rates of prescription of thrombolytic treatment to elderly patients with suspected acute myocardial infarction were identified and corrected. Streptokinase treatment was associated with transient arrhythmias or hypotension in about a third of these patients with infarcts, particularly those with electrocardiographic changes in inferior leads.

\section{Introduction}

Coronary artery thrombolysis has an established place in managing patients of all ages admitted to hospital with suspected acute myocardial infarction. ${ }^{1 \cdot 3}$ There is evidence, however, that elderly patients obtain greater benefit, in terms of absolute reduction in mortality, from treatment with streptokinase or recombinant tissue plasminogen activator than younger infarct survivors. ${ }^{2+6}$

Although the Plymouth coronary care unit has a policy of open admission and treatment regardless of age, we had an impression that few elderly patients admitted with ischaemic cardiac chest pain were receiving either streptokinase or recombinant tissue plasminogen activator. The reasons for this apparently low prescription rate may have been $(a)$ that our elderly patients had a high incidence of recognised contraindications to thrombolysis, ${ }^{4}(b)$ that admitting senior house officers were unjustifiably worried about the haemorrhagic and hypotensive complications of thrombolytic treatment in elderly patients, ${ }^{7-9}$ or $(c)$ that thrombolytic treatment was inappropriate for our elderly patients because of pre-existing chronic disease.

The primary aims of this study were $(a)$ to audit the prescription of thrombolytic treatment in elderly patients with myocardial infarction in the unit (audit 1), (b) to institute changes in clinical management if uptake of thrombolysis was less than an expected ideal standard of $50 \%$, and $(c)$ to assess the effectiveness of this intervention by reauditing prescription of streptokinase or recombinant tissue plasminogen activator in such patients admitted to the unit (audit 2). While performing this audit it was also possible to assess two outcomes of thrombolytic treatment in elderly patients: hospital mortality in patients who did and did not receive thrombolysis and incidence of adverse events during infusion of the thrombolytic agent.

\section{Patients and methods}

All patients admitted to Plymouth coronary care unit with ischaemic cardiac chest pain received aspirin unless there was a history of allergy to this drug. Patients were considered suitable to receive thrombolytic treatment, in the absence of recognised contraindications, if there was a clinical diagnosis of acute myocardial infarction with a duration of chest pain of less than $12 \mathrm{~h}$ before arrival at the unit.

\section{AUDIT 1}

The first audit was a retrospective analysis of the case notes and discharge summaries of patients aged $\geqslant 65$ years or more admitted to the unit over the five months from 1 January to 31 May 1989 . We obtained the hospital notes of patients with acute myocardial infarct who received thrombolytic treatment. Although typed discharge summaries were available for all patients who did not receive thrombolytic treatment, it was not possible to trace the notes for six patients, and these patients were not included in the analysis of reasons for omitting thrombolysis in the first audit.

Interventions - The changes in clinical practice instituted after the first audit were that $(a)$ nursing and medical staff were informed of the low thrombolysis uptake rate and $(b)$ nursing staff were instructed to question senior house officers when elderly patients with chest pain were admitted and not prescribed treatment with either streptokinase or recombinant tissue plasminogen activator.

\section{AUDIT 2}

The second audit was a prospective analysis of case notes assessing thrombolytic prescription of treatment 
to patients aged 65 or more admitted between 1 May and 30 September 1990. The case notes for each patient in the second audit were studied before the patient's discharge and we tried to ensure that medical and nursing staff were unaware of the aims of this part of the study.

\section{AUDIT INDICATORS}

We recorded the following audit indicators from the hospital notes of each elderly patient admitted with acute myocardial infarction diagnosed according to World Health Organisation criteria ${ }^{10}$ : age and sex, date and time of admission, duration of chest pain before admission, site of infarct, receipt of thrombolytic treatment, reasons for not giving thrombolytic treatment, if reason not stated whether such treatment would have been appropriate, complications of thrombolytic treatment (arrhythmia, hypotension, haemorrhage), and whether patient survived to discharge.

We also collected information from a form in each set of case notes which had been filled in prospectively by the nurse administering thrombolytic treatment, which recorded changes in pulse, blood pressure, and temperature during the period of administering thrombolytic agent and contained printouts of any change in rhythm recorded automatically by the bedside cardiac monitor during the infusion, any symptoms experienced by the patient, and whether the infusion was interrupted and restarted or interrupted and not completed.

\section{Results}

More patients were admitted during the second audit period than the first. Although the number of patients aged 65 and over increased in proportion to the total number of admissions, the proportion of patients aged 65-69 was significantly reduced (table I). During the second audit the numbers of patients admitted with angina and cardiac failure increased significantly. Although the number of patients admitted with acute myocardial infarction was similar in both audits, the proportion of patients with this diagnosis was significantly smaller in the second audit than the first (table I).

\section{UPTAKE OF THROMBOLYTIC TREATMENT}

During the first audit only 13 of $110(12 \%)$ patients with acute myocardial infarction received thrombolytic treatment compared with 55 of $119(46 \%)$ in the second audit $(p<0.01)$. No patients with a subsequent diagnosis of angina received thrombolysis in the first audit compared with 13 of $79(16 \%)$ patients with unstable angina in audit 2 .

Reasons for omitting treatment differed significantly between the two audits $\left(\mathrm{p}<0.02\right.$ by $\chi^{2}$ test) (table II). There were no significant differences in the propor-

TABLE I-Characteristics of patients admitted to coronary care unit. Figures are numbers (percentages)

\begin{tabular}{|c|c|c|c|}
\hline & Audit 1 & Audit 2 & Comparison $^{\star}$ \\
\hline Total admissions & 577 & 741 & \\
\hline Patients aged $>65$ & $264(46)$ & $370(50)$ & NS \\
\hline \multicolumn{4}{|l|}{$\begin{array}{l}\text { Age (years): } \\
\text { A }\end{array}$} \\
\hline $65-69$ & $109(41)$ & $117(32)$ & $\mathrm{p}<0.02$ \\
\hline $70-74$ & $78(30)$ & $112(30)$ & NS \\
\hline $75-80$ & $48(18)$ & $89(24)$ & NS \\
\hline$>80$ & $29(11)$ & $52(14)$ & NS \\
\hline \multicolumn{4}{|l|}{ Diagnoses: } \\
\hline Acute myocardial infarction & $110(42)$ & $119(32)$ & $\mathrm{p}<0.02$ \\
\hline Angina or pericarditis & $36(14)$ & $79(21)$ & $\mathrm{p}<0.02$ \\
\hline Arrhythmia & $57(22)$ & $89(24)$ & NS \\
\hline Cardiac failure & $6(2)$ & $28(8)$ & $p<0.01$ \\
\hline Non-cardiac pain & $13(7)$ & $22(6)$ & NS \\
\hline Other & $36(14)$ & $33(9)$ & NS \\
\hline
\end{tabular}

TABLE II-Reasons for omitting thrombolytic treatment in patients with subsequently confirmed acute myocardial infarction. Figures are numbers (percentages) of patients

\begin{tabular}{lccc}
\hline & $\begin{array}{c}\text { Audit } 1 \\
(\mathrm{n}=91)^{\star}\end{array}$ & $\begin{array}{c}\text { Audit 2 } \\
(\mathrm{n}=64)\end{array}$ & Comparison \\
\hline Contraindications & $20(22)$ & $17(27)$ & $\mathrm{NS}$ \\
$\begin{array}{l}\text { Delay in presentation } \\
\text { Delay in diagnosis }\end{array}$ & $14(15)$ & $18(28)$ & $\mathrm{NS}$ \\
$\begin{array}{l}\text { Dyspepsia } \\
\text { Unexplained or inappropriate }\end{array}$ & $25(27)$ & $23(36)$ & $\mathrm{NS}$ \\
& $22(11)$ & $1(2)$ & $\mathrm{p}<0 \cdot 05$ \\
$\mathrm{p}<0.01$
\end{tabular}

${ }^{\star}$ Excluding six patients whose case notes were missing. NS = not significant.

TABLE III-Adverse events severe enough to warrant interrupting infusion of streptokinase in 77 elderly patients admitted with either acute myocardial infarction $(n=64)$ or unstable angina $(n=13)$. Figures are numbers (percentages)

\begin{tabular}{lcc}
\hline & $\begin{array}{c}\text { Infusion } \\
\text { completed }\end{array}$ & $\begin{array}{c}\text { Infusion } \\
\text { not completed }\end{array}$ \\
\hline Bradycardia & $11(14)^{\star}$ & $1(1)$ \\
Symptomatic hypotension & $5(6)$ & $3(4)$ \\
Bleeding gums & $1(1)$ & $1(1)$ \\
Rigors & $1(1)$ & 0
\end{tabular}

ॠFour patients given intravenous atropine.

tions of patients excluded in both audits because of specific contraindications, delay in presentation after onset of chest pain, and delay in diagnosing acute myocardial infarction. Significantly more patients were excluded because of dyspepsia or for unstated reasons in audit 1 than audit $2(\mathrm{p}<0.05, \mathrm{p}<0.01$ respectively).

\section{MORTALITY AND ADVERSE EVENTS DURING INFUSION}

A total of 229 patients with acute myocardial infarction and 115 patients with unstable angina were admitted during both audit periods, of whom $68(30 \%)$ and $13(11 \%)$ respectively received thrombolysis. Only four of the 81 patients treated with thrombolysis received recombinant tissue plasminogen activator, none of whom had an adverse event during treatment and all of whom were alive at discharge.

During the first audit no patient treated with thrombolysis died before discharge and 29 of 97 $(30 \%)$ patients who did not receive thrombolysis died. During the second audit the within hospital mortality was $20 \%(11 / 55)$ for the thrombolysis group and $19 \%(12 / 64)$ for the untreated group, an overall mortality of $16 \%(11 / 68)$ with thrombolysis compared with $25 \%(41 / 161)$ without thrombolysis for both groups combined (not significant).

Streptokinase treatment was completed uneventfully in $48 / 64(75 \%)$ patients with acute myocardial infarction and in $10(77 \%)$ with angina. Treatment was interrupted and later completed in 18 patients ( 16 with infarction and two with angina), but in four patients with infarction and one with angina the infusion was interrupted and not completed. Table III shows adverse events severe enough to warrant interruption of treatment and table IV transient adverse events not severe enough to cause interruption of treatment noted by nursing staff or automatically recorded.

Twenty four patients with infarction had electrocardiographic changes in the anterior leads and 42 had changes in inferior leads (changes were indeterminate in two patients) in the group receiving thrombolysis. Interruption of treatment occurred significantly more commonly in patients with inferior than anterior infarcts $(16(38 \%) v 3(13 \%), \mathrm{p}<0 \cdot 05)$.

\section{Discussion}

The major question relating to thrombolytic treatment for acute myocardial infarction is not which agent should be employed but rather how to increase its prescription to eligible patients. Evidence in the 
United Kingdom and abroad suggests that the availability and prescription of thrombolytic treatment is too low. ${ }^{41112}$ This may have future medicolegal implications

Although a rigid upper age limit for thrombolytic treatment has been employed in clinical trials, this restriction has no rationale in routine clinical management of elderly patients with suspected acute myocardial infarction. ${ }^{13}$ Such patients derive greater benefit from thrombolysis by virtue of their increased mortality compared with young patients. One study of pooled data showed a saving of $4 \cdot 1$ lives $/ 100$ patients treated, a benefit twice that for younger patients.

In our study elderly patients with chest pain and a good quality of life were appropriately referred to our coronary care unit by their family doctors. Although our senior house officers in the unit may have been anxious about giving thrombolytic treatment to patients with dyspepsia or heartburn in the first audit, this is only a relative contraindication and without a recent history of overt bleeding the risks of treatment do not outweigh the benefits. The dramatic increase in uptake of thrombolytic treatment in the second audit may not be solely attributable to our interventions as the publicity this treatment received between the two audits may also have influenced the decisions made by medical staff in the unit. Although educational programmes alone are less effective in changing medical performance than explicit clinical guidelines or feedback control, ${ }^{14}$ the combination of a high profile of the benefits and risks of thrombolytic treatment in the medical press ${ }^{1516}$ together with the feedback from our first audit (and from nursing staff) may have helped to focus attention of medical staff on the established protocol in our hospital.

The finding that similar numbers of patients in both audits were excluded because of recognised contraindications to thrombolysis and delay in presentation to hospital and diagnosis of infarction may indicate that the proportion of patients who are not prescribed thrombolysis is relatively constant and that the ceiling for uptake of thrombolysis in our hospital is about $50-55 \%$ (the proportion of patients excluded for these three reasons representing $57 \%$ and $49 \%$ of all patients with infarction admitted in the first and second audit periods respectively). Changes in patient awareness of the significance of chest pain and in patient referral to hospital by family practitioners are needed to reduce this relatively static proportion of excluded patients. In addition, improvements in the early diagnosis of acute myocardial infarction (when electrocardiographic changes are minimal or absent ${ }^{17}$ ) will be beneficial as well as a greater readiness of senior house officers to prescribe thrombolysis in "borderline" cases of infarction or angina. The increased prescription of thrombolysis in the second audit to patients with a subsequent diagnosis of angina is encouraging in this respect.

Comparison of within hospital mortality between the patients who did and did not receive thrombolysis would not be expected to show a significant difference in view of their small numbers. Our mortality figures on discharge, however, are similar to those of the second international study of infarct survival (ISIS-2) ${ }^{\prime}$ for patients aged over 70 at five weeks for the thrombolysis and aspirin group (16\% (Plymouth) $v 15 \cdot 8 \%$ (ISIS-2).

Although early studies suggested an increased risk of haemorrhagic complications in elderly patients receiving thrombolytic treatment, ${ }^{78}$ large multicentre studies have shown that this fear is unfounded. ${ }^{14}$ In this study most $(94 \%)$ patients with suspected myocardial infarction completed the treatment with either streptokinase or recombinant tissue plasminogen activator, although in $22 \%$ the infusion was temporarily interrupted by supervising nursing staff in the unit. Treatment was associated with transient or sustained haemodynamic disturbance in $35 \%$ $(28 / 81)$ of patients, but the proportion that would have occurred without thrombolysis owing to the ischaemic process itself is unclear. Patients with inferior infarction were particularly at risk of complications with this treatment. The finding of a higher incidence of transient arrhythmias in patients with inferior infarcts is important because the benefits of thrombolytic treatment for patients with suspected acute infarction at this site are of smaller magnitude and are less certain than those for suspected anterior infarcts. ${ }^{18}$ In assessing the risk-benefit equation the finding that $38 \%$ of patients with inferior infarcts had their thrombolytic infusions interrupted because of arrhythmias or other side effects needs to be balanced against the calculation of an estimated absolute reduction of early mortality of $1 \%$ (indicating a need to treat 125 patients to save one additional life) for infarcts at this site. ${ }^{18}$ Further studies are required to assess the risks of reperfusion arrhythmias, particularly in patients with inferior ischaemia, if thrombolytic treatment is to be administered outside the setting of a coronary care unit. Overall, this study shows that audit can be associated with improvements in patient care, although a causal link between interventions and improved outcome is always hard to demonstrate. ${ }^{14}$ The auditing of routine observations performed by nursing staff can also be an important source of information relating to the possible hazards of medical practice.

We thank the consultant physicians of Derriford Hospital for allowing us to study their patients. We thank Mrs J F Stanley and Miss D F Frantom for obtaining the hospital notes.

1 ISIS-2 (Second International Study of Infarct Survival) Collaborative Group Randomised trial of intravenous streptokinase, oral aspirin, both, or neither among 17187 cases of suspected acute myocardial infarction: ISIS-2. Lancet 1988 ;ii:349-60.

2 Gruppo Italiano per lo Studio della Streptochinasi nell'Infarto Miocardico (GISSI). Effectiveness of intravenous thrombolytic treatment in acut myocardial infarction. Lancet 1986; i:397-402.

3 Wilcox RG, von der Lippe G, Olsson CG, Jensen G, Skene AM, Hampton JR. The ASSET Study Group. Trial of tissue plasminogen activator for mortality reduction in acute myocardial infarction, Anglo-Scandinavian Study of Early Thrombolysis (ASSET). Lancet 1988;ii:525-33.

4 Muller DWM, Topol EJ. Selection of patients with acute myocardia infarction for thrombolytic therapy. Ann Intern Med 1990;113:949-60.

5 Grines CL, DeMaria AN. Optimal utilization of thrombolytic therapy for acute myocardial infarction: concepts and controversies. 9 Am Coll Cardio 1990;16:223-31.

6 Sleight P. Survival following thrombolytic therapy. Eur Heart $f 1990 ; 11$ (suppl F):1-4.

7 Lew AS, Hod H, Cercek B, Shah PK, Ganz W. Mortality and morbidity rates of patients older and younger than 75 years with acute myocardial infarction of patients older and younger than 75 years with acute myocardial in
treated with intravenous streptokinase. Am $\mathcal{F}$ Cardiol 1987;59:1-5.

treated with intravenous streptokinase. Am $\mathcal{F}$ Cardiol 1987;59:1-5.
8 Aldrich MS, Sherman SA, Greenberg HS. Cerebrovascular complications of Aldrich MS, Sherman SA, Greenberg HS. Cerebr
streptokinase infusion. $\mathcal{F} A M A$ 1985;253:1777-9.

9 Lew AS, Laramee P, Cercek B, Shah PK, Ganz W. The hypotensive effect of intravenous streptokinase in patients with acute myocardial infarction. Circulation 1985; 72:1321-6.

10 World Heatlh Organisation. Public health in Europe 5. Myocardial infarction community registers. Annexe 1. Copenhagen: WHO, 1976.

11 Murray N, Lyons J, Layton C, Balcon R. What proportion of patients with myocardial infarction are suitable for thrombolysis. Br Heart $\mathcal{f}$ 1987:57: $144-7$.

12 Burrell CJ, Skehen JD, Cowley ML, Barrett CW, Mills PG. Districts' use of thrombolytic agents. BMJ 1990;300:237-8.

13 Kennedy JW. Expanding the use of thrombolytic therapy for acute myocardial infarction. Ann Intern Med 1990;113:907-8.

14 Shaw C. Medical audit. A hospital handbook. 3rd ed. London: King's Fund Centre, 1990.

15 Petch MC. Dangers of thrombolysis. BM7 1990;300:483-4.

16 Smith LDR, Coltart DJ. Reviews in medicine. Cardiology. Postgrad Med $\gamma$ 1990;66:263-79.

17 Timmis AD. Early diagnosis of acute myocardial infarction. BMJ 1990;301 $941-2$

18 Midgette AS, O'Connor GT, Baron JA, Bell J. Effect of intravenou streptokinase on early mortality in patients with suspected acute myocardial infarction. Ann Intern Med 1990;113:961-8.

(Accepted 16 October 1991) 